\title{
Aciepe Histórias Infantis e Matemática: uma instância formativa
}

\author{
Ana Paula Gestoso de Souza' \\ Rosa Maria Moraes Anunciato de Oliveira' \\ 'Universidade Federal de São Carlos (UFSCar), São Carlos/SP - Brasil
}

RESUMO - Aciepe Histórias Infantis e Matemática: uma instância formativa. Neste artigo, analisa-se a dinâmica da Atividade Curricular de Integração Ensino Pesquisa e Extensão (Aciepe) Histórias Infantis e Matemática nas séries iniciais, a partir da trajetória de cinco egressas do curso de Pedagogia, participantes da atividade. Optou-se pelo estudo de caso da Aciepe e tomaram-se como dados os depoimentos das cinco participantes, utilizando-se múltiplas fontes de coleta de dados: registros escritos produzidos ao longo da Aciepe, entrevista e questionário respondidos após o término da atividade. A análise dos dados mostra a constituição da Aciepe como uma instância formativa, respaldada pela instituição, que impulsiona o desenvolvimento profissional e a aprendizagem da docência.

Palavras-chave: Desenvolvimento Profissional. Formação Inicial. Literatura Infantojuvenil e Matemática.

ABSTRACT - Aciepe Children's Stories and Mathematics: an educational instance. This paper analyzes the dynamics of the Curricular Activity of Teaching, Research, and Extension Integration (Aciepe), called Children's Stories and Mathematics in the Elementary School, based on the trajectory of Pedagogy graduates. We chose the case study of ACIEPE, based on the account of its five participants. We analyzed multiple data sources - written records produced over this research, interviews, and questionnaires answered after the end of the activity. The results show the constitution of Aciepe as an educational instance that promotes the teacher's professional development and learning, supported by the institution.

Keywords: Professional Development. Elementary School Education. Child Literature and Mathematics.

Educação \& Realidade, Porto Alegre, v. 39, n. 4, p. 1027-1049, out./dez. 2014. 1027

Disponível em: <http://www.ufrgs.br/edu_realidade> 


\section{Introdução}

O presente artigo é originado de uma pesquisa de doutorado em Educação que buscou investigar, sob a perspectiva de egressos do curso de Pedagogia, as contribuições da Atividade Curricular de Ensino Pesquisa e Extensão (Aciepe) Histórias Infantis e Matemática nas Séries Iniciais, para o desenvolvimento do processo de aprender a ensinar matemática.

A partir dos dados obtidos foi possível realizar discussões e tecer considerações sobre as aprendizagens de egressas do curso de Pedagogia que participaram da Aciepe e discutir as contribuições da atividade curricular para o desenvolvimento docente nas dimensões pessoal e profissional dessas participantes (Souza; Oliveira, 2013).

Considerando esses resultados, um aspecto que merece ser analisado mais atentamente é a dinâmica desenvolvida na Aciepe - envolvendo estudo teórico, discussão em grupo, a construção e a utilização de um material educativo para o ensino de matemática. Neste artigo, analisa-se essa dinâmica, a partir da trajetória percorrida por cinco participantes da Aciepe. Destaca-se que nesse processo formativo a dimensão institucional é fundamental na medida em que a Instituição de Ensino Superior (IES), como instância formadora, reconhece, prestigia e promove a realização dessa modalidade formativa que se mostrou profícua ao desenvolvimento profissional docente.

\section{Desenvolvimento Profissional Docente e Formação Inicial}

Neste estudo, entende-se que o conceito de desenvolvimento profissional docente é polissêmico e se modificou ao longo da última década. Ressalta-se, também, que o desenvolvimento profissional tem um caráter intencional e pressupõe evolução e continuidade, “[...] rompendo com a tradicional justaposição entre formação inicial e continuada” (Marcelo García, 2009, p. 9).

Considera-se que o desenvolvimento profissional implica em aprendizagem e a recíproca também é verdadeira, conforme Mizukami et al., 2002. A aprendizagem da docência como um processo dinâmico e não linear, engloba mudanças e singularidades e é influenciada pelas crenças, valores e expectativas do sujeito. Assim, o desenvolvimento profissional ancora-se nas experiências formativas no período de escolarização na educação básica, na formação inicial e em cursos realizados ao longo da carreira. Além disso, é influenciado por diversos fatores como os pares, o contexto de trabalho, a família, os alunos, as políticas públicas entre outros elementos.

Nesse sentido, concebe-se a formação inicial como uma etapa do desenvolvimento profissional quando o licenciando volta-se para sua prática futura no decorrer desse processo. Isso significa que quando

1028 Educação \& Realidade, Porto Alegre, v. 39, n. 4, p. 1027-1049, out./dez. 2014. Disponível em: <http://www.ufrgs.br/edu_realidade> 
o futuro professor se coloca em movimento para analisar uma prática observada e experienciada, considerando sua prática futura, ele está se desenvolvendo profissionalmente.

Imbernón (2004) enfatiza uma formação inicial na qual, o professor, dotado de um arcabouço de conhecimentos científicos, culturais, contextuais, psicopedagógicos e pessoais, será capaz de analisar e investigar as situações educativas, tendo ciência das funções educativas, das consequências de suas decisões e do contexto social, histórico e político em que a prática escolar se insere. Sendo assim, esse docente conseguirá compreender as mudanças que ocorrem no espaço escolar e adequar o processo de ensino às necessidades formativas dos estudantes.

Almejando essa formação, destaca-se a importância do futuro professor estabelecer um contato com a prática pedagógica que exige planejamento e orientação, pois a qualidade da experiência vivida depende de como o docente em formação pensa sobre ela (Zeichner, 1993; Marcelo García; Vaillant, 2009).

Nesse cenário, destaca-se a relevância de uma formação inicial na qual as disciplinas acadêmicas possam possibilitar a aquisição de conhecimentos para a análise da prática escolar, assim como permitir certo contato com a prática pedagógica, sua investigação e compreensão, reelaborando e aprofundando as teorias e os saberes da experiência. Uma formação inicial que, segundo Gatti (2009), possibilite a compreensão da educação e do ensino e verse sobre os conhecimentos e o entendimento do sistema escolar e da escola como um sistema sociocultural com especificidades. Concretizando a formação de um docente com espírito investigativo, que domine conhecimentos teóricos e práticos da didática e das práticas de ensino, conectados aos conhecimentos disciplinares e interdisciplinares.

Ao voltar o olhar para a formação inicial do professor que ensina matemática nos anos iniciais do Ensino Fundamental (EF), Nacarato, Mengali e Passos (2009) destacam que, muitas vezes, a realidade formativa de futuros professores não engloba efetivamente as tendências atuais do ensino de matemática. De acordo com as autoras,

$$
\begin{aligned}
& \text { [...] podemos, então dizer que as futuras professoras po- } \\
& \text { livalentes têm tido poucas oportunidades para uma for- } \\
& \text { mação matemática que possa fazer frente às atuais exi- } \\
& \text { gências da sociedade e, quando ela ocorre na formação } \\
& \text { inicial, vem se pautando nos aspectos metodológicos } \\
& \text { (Nacarato; Mengali; Passos, 2009, p. 22). }
\end{aligned}
$$

Ainda na perspectiva das autoras, muitas das crenças que os futuros professores possuem sobre a matemática, seu ensino e sua aprendizagem podem influenciar fortemente a construção da prática profissional. É comum que esses sujeitos, em formação, tenham uma visão utilitarista da matemática, concebendo-a como uma ferramenta e con-

Educação \& Realidade, Porto Alegre, v. 39, n. 4, p. 1027-1049, out./dez. 2014.1029 Disponível em: <http://www.ufrgs.br/edu_realidade> 
siderando que um dos aspectos mais importantes da matemática escolar são os procedimentos de cálculos; isso acaba gerando um ensino que enfatiza as regras e os procedimentos.

Considerando esses apontamentos, elenca-se o papel importante da formação inicial em possibilitar que os futuros professores dos anos iniciais se desvencilhem de uma possível relação negativa com a matemática e da visão de que essa matéria se resume a aplicação de procedimentos e operações. É nesse cenário que se situa a Aciepe Histórias Infantis e Matemática nas Séries Iniciais como uma instância formativa que impulsiona o desenvolvimento profissional envolvendo literatura infantojuvenil e matemática.

\section{A Aciepe Histórias Infantis e Matemática nas Séries Iniciais}

A Atividade Curricular de Integração Ensino Pesquisa e Extensão - Aciepe - é uma proposta da Universidade Federal de São Carlos que envolve professores, técnicos e alunos da universidade e outros sujeitos da sociedade visando articular Ensino, Pesquisa e Extensão, e que pode ser oferecida por qualquer departamento da universidade, sob a coordenação de um ou mais professores responsáveis. A atividade conta com apoio financeiro da Pró-Reitoria de Extensão da UFSCar na compra de material de consumo e permanente, de passagens para palestrantes externos e concessão de bolsas de monitoria para os graduandos da instituição.

A Aciepe Histórias Infantis e Matemática nas Séries Iniciais foi ofertada entre 2004 e 2010, sob a coordenação das professoras Cármen Lúcia Brancaglion Passos e Rosa Maria Moraes Anunciato de Oliveira. Tinha como público-alvo estudantes dos cursos de Pedagogia e de Licenciatura em Matemática e professores da Educação Básica. Foram desenvolvidas as seguintes atividades: o estudo e discussão com o grupo de referenciais que abordavam a língua materna, a linguagem matemática, as potencialidades da leitura, o ensino de matemática e a conexão entre literatura infantil e matemática; a análise, construção e posterior aplicação de livros infantis com conteúdos matemáticos. O processo de elaboração dos livros era socializado com o grupo, possibilitando que os participantes compartilhassem experiências e saberes, traçassem objetivos para mudanças e tecessem sugestões.

Essa Aciepe constituiu um grupo que possuía características do trabalho colaborativo, a saber: voluntariedade, apoio intelectual, técnico e afetivo, respeito mútuo, diálogo e negociação. O termo colaborativo é utilizado na perspectiva de Hargreaves (1998) que apresenta os aspectos do trabalho colaborativo: voluntariedade, identidade, espontaneidade, liderança compartilhada ou corresponsabilidade, apoio e respeito mútuo. Fiorentini (2004) aponta outros aspectos do grupo colaborativo, os quais, de certa forma, são envolvidos pelas característi-

1030 Educação \& Realidade, Porto Alegre, v. 39, n. 4, p. 1027-1049, out./dez. 2014 Disponível em: <http://www.ufrgs.br/edu_realidade> 
cas assinaladas por Hargreaves (1998): ação e reflexão compartilhadas, diálogo, negociação, confiança mútua, entre outros.

Estudos como, por exemplo, Nacarato et. al (2006), Ferreira (2006), Passos, Oliveira e Gama (2007) dentre outros, mostram que os grupos colaborativos facilitam e estimulam o desenvolvimento profissional propiciando a aprendizagem dos professores.

Especificamente sobre a Aciepe mencionada Passos, Oliveira e Gama (2007, p. 153) ressaltam que:

[...] o compartilhar colaborativo do grupo, com participantes de áreas diversas, tem-se constituído num espaço de reflexão, possibilitando-lhes revisitar a formação matemática, (re)significar conceitos, tendo a prática pedagógica docente como eixo das reflexões produzidas (Passos; Oliveira; Gama, 2007, p. 153).

Outra característica importante da Aciepe é a produção de um material educativo pelos participantes. Davis e Krajcik (2005) indicam que os materiais educativos curriculares são capazes de ajudar o educador tanto a aprender fatos e conceitos de conteúdos específicos, como também a antecipar e a interpretar o que os alunos podem pensar sobre determinado conteúdo ou fazer em resposta às atividades de ensino propostas. E também são um suporte para compreensão das representações dos conteúdos.

Davis e Krajcik (2005) ainda ressaltam que os materiais curriculares possibilitam que os professores atentem para as ideias subjacentes que orientam suas ações, promovendo certa autonomia docente e auxiliando-os a tomarem decisões sobre como adaptar as matérias do currículo às determinadas características dos alunos e aos contextos de ensino.

Diante dessas acepções, é possível vislumbrar as potencialidades formativas do processo de elaborar materiais educativos, sendo necessário também considerar o alerta dos autores ao afirmarem que esses materiais não podem ser vistos como uma panaceia.

\section{Metodologia e Procedimentos Metodológicos}

Neste artigo, analisa-se a dinâmica desenvolvida na Aciepe Histórias Infantis e Matemática nas Séries Iniciais - estudo teórico, discussão em grupo, a construção e a utilização de um material educativo para o ensino de matemática - a partir da trajetória percorrida por cinco egressas do curso de Pedagogia.

Esta investigação aproximou-se da estratégia de pesquisa de estudo de caso e referenda as ideias de André (1984; 2005), para quem o objetivo do estudo de caso é compreender a situação como ela é realmente. Trata-se de uma pesquisa de uma unidade específica, situada

Educação \& Realidade, Porto Alegre, v. 39, n. 4, p. 1027-1049, out./dez. 2014.1031 Disponível em: <http://www.ufrgs.br/edu_realidade> 
em determinado contexto. Por isso, uma das vantagens desse tipo de estudo é que ele propicia uma visão aprofundada, ampla e integrada da unidade investigada.

O interesse pelo particular não implica em perder a noção do todo e desvincular o caso do contexto. Por outro lado, um pressuposto básico é que "[...] uma apreensão mais completa do objeto só é possível se for levado em conta o contexto no qual este se insere” (André, 1984, p. 52). Além disso, o estudo de caso possibilita que seja feita generalização naturalísticas. A partir da leitura, da descrição densa do caso, do contexto, dos sujeitos e das relações que esses elementos estabelecem, o leitor indagará e decidirá se as interpretações, as ideias e as hipóteses apresentadas no estudo podem ser aplicadas à sua situação de interesse.

Considerando essas características e pressupostos, destaca-se a Aciepe como o caso analisado e as histórias das participantes configuram-no. As especificidades do processo investigado referem-se ao fato de que as aprendizagens proporcionadas pela Aciepe ocorreram em um contexto de formação com uma dinâmica e características específicas, concretizado pelo suporte da instituição formativa.

Foram contatadas nove das 18 egressas do curso de Pedagogia que participaram da Aciepe entre 2004 e 2010, em razão de elas terem utilizado o livro elaborado na atividade curricular em situações de ensino e aprendizagem na graduação. Dentre elas, cinco aceitaram participar da pesquisa: Ana, Thaís, Daiana, Marcela e Maria Luiza.

Considerando o apontado por André (1984; 2005), a abordagem metodológica do estudo de caso exige o uso de duas ou mais fontes de evidências para a coleta de dados e uma descrição aprofundada do fenômeno. Em razão disso, utilizaram-se múltiplas fontes de coleta de dados, a saber: os registros existentes, elaborados pelos estudantes do curso de Pedagogia que participaram da Aciepe e pelas monitoras, considerando o período indicado ${ }^{1}$, entrevista semiestruturada e questionários abertos respondidos após o término da Aciepe ${ }^{2}$.

Para compreender como a Aciepe se configurou como instância formativa de professores buscou-se nos dados sobre a trajetória das egressas, indícios indicando que os materiais educativos podem se configurar como ferramentas potencializadoras de aprendizagens das participantes e podem promover o desenvolvimento de uma disposição para a reflexão.

As participantes mostraram que a dinâmica proposta pela atividade de extensão foi um ambiente no qual houve espontaneidade, apoio intelectual, técnico e afetivo, respeito mútuo, ação e reflexão compartilhadas, diálogo e negociação - elementos característicos de um grupo colaborativo.

A seguir, apresenta-se e analisa-se com mais detalhe a trajetória percorrida pelas cinco participantes da Aciepe. Para tanto, em um primeiro momento destaca-se o motivo que as levou a cursar a atividade e

1032 Educação \& Realidade, Porto Alegre, v. 39, n. 4, p. 1027-1049, out./dez. 2014. Disponível em: <http://www.ufrgs.br/edu_realidade> 
o processo de elaboração dos livros. Em seguida, expõem-se o processo de implementação dos livros.

\section{As Histórias Infantis com Conteúdos Matemáticos}

Ana buscou participar da Aciepe, nos anos de 2008 e 2009, para aprofundar seus conhecimentos sobre o ensino de matemática e elaborou dois livros: Papai Noel existe! Mas já não se lembra mais e Herlock Sholmes - e o famoso caso do papai Noel. Em ambos os enredos, o Papai Noel sofre um atentado que gera uma série de dúvidas em relação ao criminoso e o leitor é convidado a descobrir quem é o autor do crime.

O primeiro livro apresentava três desfechos e, ao final de cada um deles, havia vários problemas matemáticos para o leitor resolver. Os conteúdos dos problemas propostos foram: proporção, adição, subtração, multiplicação, dobro, metade e porcentagem. No segundo livro, o detetive Herlock Sholmes precisava resolver alguns problemas matemáticos, apresentados ao longo da história, e o leitor é convidado a solucioná-los. Os conteúdos dos problemas foram: leitura de gráficos, proporção, adição, subtração e multiplicação, dobro e metade, porcentagem, fração e lógica.

Ana apontou que ao realizar os estudos teóricos da Aciepe percebeu a necessidade de superar as experiências vividas no período escolarização, pois compreendeu que os alunos precisavam ir além da realização de procedimentos. Conforme se observa nas palavras de Ana.

[Na escola] eu pegava o problema, tirava todos os elementos resolvia e dava certo, só que quando caía em problemas ou de lógica, ou problemas reais, era muito difícil para eu resolver, porque eu tinha várias opções e cada uma das opções eliminava todas as outras. Ai eu pensei: por que eliminar todas as outras, por que não manter todas as outras opções? E daí eu pensei nisso e fiz um livro com o tema resolução de problemas de matemática, e os problemas todos têm várias respostas (Transcrição - Encerramento da ACIEPE: 01-07-08).

Por outro lado, Ana escolheu os conteúdos por ter segurança em abordá-los. Porém, apontou que no processo de elaboração dos livros teve dificuldades em conectar o enredo e o conteúdo matemático com a faixa etária dos alunos dos anos iniciais do EF.

No primeiro livro Ana não conseguiu colocar em prática sua ideia de elaborar uma narrativa na qual a continuidade da história dependia da resolução dos problemas. Ela elaborou problemas, que aparecem no final da história, cuja resolução não depende da leitura do livro.

Contudo, Ana superou essa dificuldade ao cursar novamente a ACIEPE em 2009. Em razão da narrativa do segundo livro ser semelhante a do primeiro, Ana afirmou não precisou se preocupar com a elaboração do enredo e se atentou mais para os problemas matemáticos.

Educação \& Realidade, Porto Alegre, v. 39, n. 4, p. 1027-1049, out./dez. 2014.1033 Disponível em: <http://www.ufrgs.br/edu_realidade> 
Na trajetória percorrida por Ana, destaca-se que as discussões coletivas sobre o livro elaborado foram momentos importantes e auxiliaram em sua aprendizagem. Ana apontou que o compartilhar a experiência foi um momento facilitador do processo, sendo que esse compartilhar não ocorreu somente com os participantes da Aciepe, mas também com seus familiares. Além disso, Ana comentou que dialogar com professoras do EF proporcionou certo contato com a prática docente, possibilitando reduzir um pouco a distância, tão criticada, entre a universidade e a escola. Nas palavras de Ana:

É muito bom ouvir tanto as pessoas já formadas como as iniciantes, já que das pessoas formadas podemos retirar respostas e muitas vezes resolução para nossos problemas, e dos iniciantes podemos tirar perguntas que explicam melhor os nossos questionamentos que nem sabíamos que tínhamos. Os professores do ensino fundamental nos trazem situações reais sobre as quais podemos refletir (Ficha de avaliação da ACIEPE 2009).

[...] Ao fazer o plano de aula, fiquei presa ao conteúdo matemático abordado, porém, com a ajuda de algumas professoras [da ACIEPE] consegui incluir algumas atividades envolvendo a escrita, interpretação e produção de texto (TCC, 2010, p. 34).

Ana também apontou que a interlocução com alunos do curso de matemática lhe auxiliou na compreensão do conteúdo específico. Ademais, ressaltou que a participação de formadoras de diferentes áreas contribuiu para atentar o conteúdo abordado.

Assim como Ana, Thaís escolheu cursar a Aciepe pelo fato de gostar de matemática. No ano de 2005, Thaís elaborou o livro Por que aprender matemática? No qual Pedrinho, o personagem principal - que considerava matemática uma disciplina difícil - precisou resolver dois problemas matemáticos que abordavam o conceito de dúzia, dezena e adição. Um dos problemas foi solucionado em uma feira livre e, o outro, no sítio de sua avó. No final da narrativa, Pedrinho mostrou para a professora que conseguiu concluir a tarefa e aprender os conteúdos.

Thaís ressaltou que escolheu os conteúdos em razão de serem utilizados no dia a dia e porque são ensinados logo no início da escolarização (Questionário de Thaís).

Sua expectativa era que o livro fosse motivador e conseguisse promover a aprendizagem dos alunos que apresentem dificuldades com os conteúdos matemáticos abordados. O trecho a seguir ilustra essa perspectiva.

O livro também tem por objetivo auxiliar a aprendizagem de alunos (as) com dificuldades e/ou desinteresse nesta área de conhecimento, para que estes possam se envolver com a disciplina de tal maneira que esta se torne atraente e os conhecimentos adquiridos nesta [disciplina] sejam significativos para eles (Plano de aula elaborado por Thaís).

1034 Educação \& Realidade, Porto Alegre, v. 39, n. 4, p. 1027-1049, out./dez. 2014 Disponível em: <http://www.ufrgs.br/edu_realidade> 
Além disso, Thaís considerou importante trabalhar com a resolução de problemas conectados com o enredo da narrativa, para ela é fundamental propor situações que requeiram uma solução matemática e que permitam o levantamento de questões, pesquisa, discussão, exploração e especulação, além da contextualização das operações (Plano de aula elaborado por Thaís).

Ao relatar o processo de construção do livro, Thaís também apontou as dificuldades encontradas: dificuldades em conectar enredo e conteúdo e concretizar um ensino atrativo para o aluno que o motivasse a realizar atividades propostas. Nessa dinâmica foi necessário fazer mudanças no enredo para inserir o conteúdo. Os trechos a seguir ilustram essas considerações:

Dificuldades em unir os problemas matemáticos com a narração, para que ocorra uma sequência de fatos pertinentes e que estes despertem interesse ao leitor, para que se interessem pela leitura, além de que este tente também resolver os problemas propostos, se interessando pelo aprendizado dos conteúdos matemáticos em questão (Diário de campo de Thaís).

[Superei a dificuldade] adequando, mudando partes da história, para poder inseri-los (Questionário de Thaís).

Mesmo diante das dificuldades Thaís ressaltou que o processo de construir o livro foi satisfatório e sentiu-se bem em perceber que tem capacidade de produzir um material educativo que possibilita motivar o aluno a estudar.

Outro apontamento de Thaís refere-se a pertinência das discussões, na Aciepe, que envolveram os estudos teóricos e os livros elaborados, para ela esses momentos favoreceram, pois foram feitas discussões dos textos teóricos sobre a temática durante as aulas. Foi importante para as discussões sobre as dificuldades encontradas e as reflexões de como poder saná-las (Questionário de Thaís).

Thaís também assinalou que o fato de ter mais de uma professora responsável pela disciplina, com formação diferente, possibilitou a troca de experiência entre as áreas. Em seu depoimento destacou que as dúvidas puderam ser respondidas por um dos professores, dependendo da relação que tinha entre a pergunta/indagação com a formação do professor (Questionário de Thaís).

A terceira participante desta pesquisa foi Marcela que decidiu participar da Aciepe, no ano de 2005, por considerar interessante a metodologia de ensino proposta. Elaborou e aplicou o livro Uma casa nem tão mal assombrada, que narra à história de um grupo de amigos que entrou em uma casa aparentemente mal assombrada e lá descobriu que a dona é uma simpática senhora, que lhes serviu um lanche com bolos e tortas. O conteúdo abordado foi a noção de fração enquanto subconstruto parte-todo e a soma de frações que possuem o mesmo denomina-

Educação \& Realidade, Porto Alegre, v. 39, n. 4, p. 1027-1049, out./dez. 2014.1035 Disponível em: <http://www.ufrgs.br/edu_realidade> 
dor. Destaca-se também que, para Marcela, ilustrações e as atividades que o livro apresenta ao leitor são importantes para gerar aprendizagem.

A primeira ideia de Marcela para o livro envolveu a abordagem de um conteúdo relacionado à porcentagem, pois considerava um conceito fácil de ser abordado no cotidiano das crianças (Diário de campo de Marcela). Ela pretendia elaborar um enredo no qual a personagem Bia precisava comprar os presentes de natal para sua família, a intenção também era fazer um livro interativo apresentando perguntas ao leitor.

Mas, no decorrer do processo, verifica-se que Marcela encontrou dificuldades em abordar o conteúdo e em elaborar a narrativa. Durante o processo de elaboração do livro ela fez o seguinte relato:

Ainda preciso amadurecer a ideia sobre o tema, mas acredito que seja esse mesmo [porcentagem], mas ainda não sei como abordá-lo. Estou ainda pensando em um conflito para a narrativa (Diário de campo de Marcela).

Depois de reformular a história três vezes, Marcela decidiu abordar o conteúdo de fração por considerar que seria mais fácil desenvolver a história. O depoimento apresentado a seguir mostra sua justificativa:

A mudança aconteceu porque não consegui elaborar uma história interessante em que pudesse conciliar com o conteúdo de porcentagem. [...] Mudei a forma de construir o livro. Primeiro pensei no enredo da história e o conteúdo de fração foi o mais fácil para encaixar nesse enredo e também de ilustrar (Questionário de Marcela).

Segundo Marcela, nesse processo, a ajuda de seus amigos foi uma forma de apoio e incentivo e versou sobre a elaboração do enredo, a forma de expor os conteúdos, as ilustrações.

Procurei ajuda de alguns amigos e juntos pensamos em como superar. Amigos da Aciepe e amigos de outros cursos que não participavam. Uma amiga me ajudou nas ilustrações do livro, dei as ideias e ela colocou em prática, pois tinha muita facilidade com desenhos. Outros amigos me ajudaram ouvindo minhas angústias sobre as dificuldades que encontrava e sempre davam palpites para melhorar o enredo, a forma como iria expor o conteúdo e palavras de motivações dizendo que eu era capaz (Questionário de Marcela).

Marcela também relatou que a discussão coletiva sobre o processo de elaboração do livro foi apropriada, pois os participantes da Aciepe apresentavam visões diferentes sobre uma mesma situação.

Além disso, ela apontou que considerou pertinente a Aciepe ser de responsabilidade de mais uma professora com formação diferente,

[...] pois essa Aciepe abrange três focos: conteúdo matemático, língua portuguesa e didática, [que] contemplam vertentes de aprendizagem fundamentais que um professor deve ter: conhecimentos matemáticos,

1036 Educação \& Realidade, Porto Alegre, v. 39, n. 4, p. 1027-1049, out./dez. 2014 Disponível em: <http://www.ufrgs.br/edu_realidade> 
metodologia para passar esses conhecimentos e uma boa escrita e fala da nossa língua (Questionário de Marcela).

Diferentemente das três participantes apresentadas anteriormente, Daiana destacou que não gostava muito de matemática e buscou participar da Aciepe, em 2006, para aprofundar seus conhecimentos sobre o ensino de matemática. Elaborou o livro A cara quadrada cujo enredo inicia-se com um quadrado triste por não conhecer outros quadrados. O cubo tentou animá-lo explicando que ele é formado por quadrados e, no decorrer da história, apresentou-lhe outras formas geométricas. O conteúdo matemático abordado no livro envolve as características e propriedades das seguintes formas geométricas planas e espaciais: quadrado, triângulo, retângulo, círculo, cubo, pirâmide, esfera e bloco retangular. Ao final do livro, foram apresentadas atividades para o leitor resolver.

A escolha do conteúdo abordado por Daiana reflete sua busca pela superação de uma dificuldade relacionada ao conteúdo de geometria. Nas palavras de Daiana, a preocupação em escolher o conteúdo foi: como vou ensinar geometria se não sei geometria? (Questionário de Daiana).

Daiana também procurou elaborar um livro prazeroso. Porém, relatou que as maiores dificuldade foram com relação aos conceitos matemáticos abordados mesmo. Principalmente em como colocá-los de forma que as crianças entendessem (Questionário de Daiana).

Nesse processo a ajuda das professoras formadoras, as discussões coletivas com os professores e os alunos de graduação e os estudos do conteúdo matemático foram elementos importantes para a superação das dificuldades. Os depoimentos a seguir ilustram esses apontamentos:

[As discussões nas aulas com os colegas e professores sobre as suas ideias sobre o livro] trouxeram novas ideias e apontaram os equívocos. [...] A experiência foi ótima, pois pudemos perceber o quanto as dificuldades em Matemática não existiam apenas na Pedagogia, mas em outros cursos, bem como com as colegas que já atuavam na Educação Básica.

[...] profissionais com formações diferentes e visões diferentes do contexto escolar enriquecem demais a formação docente. Isso me ajudou muito, pois fez com que eu percebesse que a matemática é uma disciplina que pode ser fácil de ser aprendida (Questionário de Daiana).

A quinta participante deste estudo, Maria Luzia, escolheu cursar a Aciepe, em 2006, pois se sentiu motivada a escrever um livro e elaborou a história Uma tarde na marcenaria, que tem Paulo como personagem principal. No enredo, a professora de Paulo propôs aos alunos que observassem objetos e figuras e atentassem para situações que envolvessem a geometria. A partir disso, Paulo e seu amigo desenvolveram um olhar observador aos objetos e, ao observarem o pai de Paulo construir uma cadeira, aprenderam algumas propriedades das formas geomé-

Educação \& Realidade, Porto Alegre, v. 39, n. 4, p. 1027-1049, out./dez. 2014.1037 Disponível em: <http://www.ufrgs.br/edu_realidade> 
tricas. Os conteúdos matemáticos abordados na narrativa envolveram as propriedades das seguintes formas geométricas: círculo, retângulo, quadrado, cilindro e triângulo isósceles. As ilustrações são um auxilio na compreensão da história e do conceito matemático abordado.

Verificou-se que $a$ escolha de Maria Luzia pelo conteúdo matemático esteve relacionada ao fato da professora responsável pela disciplina Metodologia de Ensino de Matemática destacar que, muitas vezes, o ensino da geometria é negligenciado pelos professores dos anos iniciais. Além disso, Maria Luzia apontou que é fundamental que o aluno compreenda os conceitos, as origens deles e a utilidade do que está aprendendo.

Ela relatou que foi difícil elaborar o enredo e conectá-lo com o conteúdo matemático. A sua preocupação era que a narrativa não ficasse com um caráter técnico. Por isso, Maria Luzia conversou com mães e crianças para coletar informações sobre quais situações seriam interessantes de serem abordados na história e qual seria a melhor linguagem. Os trechos do depoimento dela mostram esse processo:

Questionei varias mães, crianças e depois comecei a esboçar a história, embasei a história em duas crianças na faixa dos 8 anos com que eu convivia (a parte psicológica), o tema central a marcenaria busquei na história das construções, um pouco bíblico, essa questão de marcenaria, mas o meu ponto central está na estrutura familiar superando possíveis problemas, porque seria fácil montar uma família com pai, mãe e filho, só que muitos não tem (Questionário de Maria Luzia).

Maria Luzia também conversou com familiares e com colegas dos cursos de Pedagogia, Matemática e Engenharia, fez estudos teóricos sobre a temática e o conteúdo. A partir disso ela corrigiu os erros conceituais e modificou o enredo várias vezes. Além disso, Maria Luzia comentou que o diálogo com professoras do EF possibilitou conhecer um pouco sobre a prática docente, conhecer as dificuldades e as experiências dessas professoras.

Percebe-se como foi importante o compartilhar suas ideias e dificuldades com outras pessoas, sejam professores, especialistas em matemática ou não.

Conforme mostram os dados as participantes se mobilizaram para aprender o conteúdo matemático abordado em seus livros e apresentaram dificuldades em conectar a matemática, a língua materna e o registro pictórico.

Observa-se que diante dessas dificuldades enfrentadas na elaboração dos livros, as futuras professoras se envolveram em experiências de investigação do conteúdo matemático e das maneiras como esse conteúdo deveria ser abordado nos materiais. Investigaram também a literatura e ilustrações que agradam às crianças.

Enfim, a elaboração do livro se configurou como uma oportunidade de reflexão sobre o ensino e a aprendizagem de conteúdos mate-

1038 Educação \& Realidade, Porto Alegre, v. 39, n. 4, p. 1027-1049, out./dez. 2014 Disponível em: <http://www.ufrgs.br/edu_realidade> 
máticos, validando o exposto por Davis e Krajcik (2005). Esses autores também afirmam que a produção de materiais curriculares pode possibilitar o desenvolvimento da autonomia docente.

Assim, infere-se que as decisões e ações que as participantes tiveram na produção do livro podem possibilitar a conexão de ideias específicas e princípios mais gerais e reconhecer diferentes formas de transpor um conhecimento adquirido em determinada situação para outra. Um exemplo de ideia geral é a justificativa da escolha de uma abordagem particular de ensino a ser utilizada no livro, e a ideia específica à abordagem instrucional de determinado conteúdo. A articulação dessas ideias possibilitou que as participantes olhassem mais atentamente para o planejamento dos livros e consequentemente para os objetivos de aprendizagem delineados.

Passos, Oliveira e Gama destacam que abordar conteúdos matemáticos a partir de histórias infantis é uma metodologia que proporciona uma prática docente de “[...] atitude inquieta da pergunta, do conflito narrativo que leva à reflexão, à aposta na postura de descobrir a matemática mais que na postura de ensinar a matemática que se conhece" (Passos; Oliveira; Gama, 2007, p. 3).

Observa-se que as participantes desenvolveram essa atitude inquieta e que foi um processo permeado por algumas dificuldades. Por outro lado, também foi enriquecedor; o "olhar para si”, o "olhar para o outro e do outro" (Gama, 2007, p. 189) são elementos que estiveram presentes na Aciepe e auxiliaram na elaboração do livro, oportunizando a compreensão do conteúdo específico, a definição do enredo, dos modos de abordar a linguagem matemática e as diferentes formas de abordar um conteúdo específico.

Constata-se o quanto esses olhares foram significativos para as egressas, principalmente o olhar para e das professoras do EF que contribuíram apresentando suas experiências. Além disso, a interlocução com o outro se colocou além da Aciepe e se conectou com a vida pessoal das participantes. Nesse cenário, é importante considerar que o olhar para a prática do outro, proposto por Shulman (2004), também é fonte de aprendizagem.

\section{A Implementação do Livro em Sala de Aula}

Ao realizar seu trabalho de conclusão de curso (TCC) da graduação, Ana utilizou o livro Papai Noel existe! Mas já não se lembra mais em uma $5^{\text {a }}$ série de uma escola pública. Nessas aulas Ana pretendeu que os alunos compreendessem a importância da leitura, resolvessem problemas, valorizassem o trabalho em grupo e se posicionassem de forma crítica. Ao relatar essa experiência, em seu TCC e na entrevista desta pesquisa, ela destacou as dificuldades encontradas nesse processo e os momentos que lhe geraram satisfação.

Educação \& Realidade, Porto Alegre, v. 39, n. 4, p. 1027-1049, out./dez. 2014.1039 Disponível em: <http://www.ufrgs.br/edu_realidade> 
A ansiedade, o controlar o tempo das aulas e algumas preocupações em relação ao ensino e uso do material produzido na ACIEPE, foram elementos elencados por Ana como dificultadores ao utilizar o livro. Os trechos dos depoimentos apresentados a seguir ilustram algumas dessas dificuldades:

[Gerenciamento do tempo] Foi muito difícil para eu fazer um plano de aula que tivesse apenas algumas horas de duração. Primeiro porque as questões propostas no livro possibilitam uma infinidade de respostas, todas corretas e eu poderia passar dias explicando porque estão todas certas; E depois porque eu consigo visualizar, durante a história, muitos assuntos, questões e temas referentes a outras disciplinas que também poderiam ser trabalhados em aulas interdisciplinares (TCC de Ana, 2010 p. 33).

[Preocupação específica com o modo de ensinar e uso do material produzido] Eu tenho uma preocupação grande de não conseguir atingir o que eu quero com a criança lendo sozinha, eu quero explicar (Entrevista de Ana).

Ana também relatou algumas tomadas de decisões que teve, durante as aulas, diante das dificuldades encontradas. Ao planejar a aula para o segundo dia, Ana, não pensou no que poderia acontecer com os alunos que faltaram na aula anterior, isso gerou uma situação que exigiu uma ação imediata.

[Retomando a aula em outro dia] Depois de feita a leitura, pedi para que o grupo formado pelos alunos faltantes resolvesse as questões propostas enquanto eu resolveria na lousa as questões que eu não conseguira resolver na última aula. Logo ao começar a resolução da questão três, ouvi risadinhas e percebi que o grupo incumbido de resolver as questões estava olhando e copiando tudo o que eu escrevia na lousa. Percebi minha falha e pedi para que eles resolvessem somente a primeira e a segunda questão e que prestassem atenção na sequência da aula (TCC de Ana, p. 48).

Em outro momento, diante da falta de compreensão de alguns alunos sobre a forma como um grupo realizou um problema, Ana interviu e explicou de outra maneira, o processo percorrido pelo grupo. $\mathrm{O}$ depoimento a seguir ilustra esse momento:

Nessa questão - Se ele trabalhasse 6 horas por dia, quanto ele teria que receber por hora trabalhada para que continuasse ganhando o mesmo que ganha agora? - pedi para os integrantes do grupo 4, que fez de cabeça me explicarem e eles disseram que para o Duende trabalhar a metade do tempo e receber a mesma coisa, deveria receber o dobro do valor estipulado por hora. Apesar da explicação um tanto quanto clara, os outros não entenderam muito bem, portanto resolvi na lousa com eles (TCC de Ana, p. 49-50).

Mesmo diante das dificuldades, Ana, relatou que ficou satisfeita pelos alunos terem participado da aula ativamente e também em ter observado o processo de raciocínio que desenvolveram ao realizarem as atividades.

1040 Educação \& Realidade, Porto Alegre, v. 39, n. 4, p. 1027-1049, out./dez. 2014 Disponível em: <http://www.ufrgs.br/edu_realidade> 
Assim como Ana, Thaís fez um planejamento detalhado das aulas nas quais aplicou o livro elaborado na Aciepe em uma turma de $3^{\text {a }}$ série de uma escola da rede Estadual de São Paulo. A aula desenvolvida por Thaís objetivou utilizar a narrativa para propor problemas matemáticos de raciocínio lógico, os quais demonstrarão aos (às) alunos (as) a importância da matemática no dia-a-dia (Plano de aula de Thaís).

Thaís destacou duas dificuldades vivenciadas na implementação do livro: gerenciar os imprevistos do cotidiano escolar, como por exemplo, uma pessoa que foi à sala de aula divulgar a venda de produtos a ser revertida para uma campanha que atende crianças com câncer, e gerenciar os comportamentos inadequados dos alunos Os excertos expostos a seguir mostram uma dessas situações.

No desenvolvimento da leitura os alunos se mostraram interessados e houve silêncio, com exceção de um grupo, o qual se dispersava e a todo momento perdia a sequência da história e não conseguia acompanhar pelo livro, fato que procurei solucionar em todos os momentos que percebi, motivo pelo qual foi preciso em um momento dar uma pequena pausa na leitura (Relatório sobre a utilização do livro p. 8).

Ao avaliar as aulas Thaís ressaltou que percebeu a aprendizagem dos alunos, conforme se observa a seguir:

Esta aula possibilitou que os que não dominavam os conceitos de dezena e dúzia pudessem aprendê-los de maneira atraente e permitiu a reflexão de como resolver um problema matemático envolvendo raciocínio lógico à alunos com dificuldades neste aspecto (Relatório de Thaís sobre a utilização do livro).

Marcela também aplicou seu livro em uma terceira série de uma escola Estadual e relatou que não encontrou dificuldades no momento de planejamento da aula, sua meta era desenvolver atividades que garantissem a interação dos alunos. A expectativa de Marcela era que o livro possibilitasse a discussão do conceito de fração e considerava que as ilustrações eram fundamentais para a aprendizagem. Segundo ela o resultado foi positivo e os estudantes participaram ativamente da aula.

Marcela relatou que a maior dificuldade que encontrou ao utilizar o livro foi saber gerenciar a sala de aula de forma que cada aluno pudesse falar em determinado momento e que ela pudesse atender as dúvidas e colocações dos alunos. Para lidar com essa dificuldade ela optou pela seguinte estratégia: quando fazia alguma pergunta esperava a resposta de todos ou ia de grupo em grupo. Assim tinha certeza de que todos estavam acompanhando a aula (Relatório de Marcela sobre a utilização do livro). Verifica-se que Marcela optou por dar espaço para os alunos exporem seus pensamentos e fazer atendimentos nos grupos dos alunos, dessa forma se certificou de que não deixava nenhum aluno a própria sorte.

Outra participante, Daiane, aplicou seu livro em uma $4^{\text {a }}$ série do EF. A sua proposta ao trabalhar com o livro foi: que a literatura pode aju-

Educação \& Realidade, Porto Alegre, v. 39, n. 4, p. 1027-1049, out./dez. 2014. 1041 Disponível em: <http://www.ufrgs.br/edu_realidade> 
dar a criança a perceber as formas geométricas existentes no mundo, além de proporcionar ao educando um novo conhecimento em sua vida (Plano de aula de Daiane). Como objetivo geral da aula Daiana pretendeu que os alunos identificassem as figuras geométricas presentes na narrativa e suas representações.

Ao utilizar o livro, a maior dificuldade encontrada por Daiana foi gerenciar a sala de aula. Para enfrentar essa dificuldade Daiana utilizou-se de regras de conduta. Conforme se observa a seguir:

Peço então para que se dividam em grupos de 4 pessoas e os ajudo a se organizarem - neste momento a sala fala muito e vira uma bagunça. A sala não fica muito quieta e chamo as regras diversas vezes.

[...] A sala estava agitada, mas as regras foram fundamentais para que eu conseguisse fazer as atividades propostas no plano (Relatório de Daiana sobre a utilização do livro).

Outra dificuldade encontrada por Daiana foi gerenciar o tempo das atividades realizadas pelos estudantes, ela não conseguiu propor algumas atividades que havia planejado.

Para além das dificuldades Daiana ressaltou que utilizar o livro proporcionou-lhe satisfação ao perceber o engajamento e a aprendizagem de uma aluna que possui necessidades educativas especiais.

[sobre a aluna com deficiência] Um fator que me deixou muito feliz foi ter conseguido ensinar as formas geométricas (pelo menos uma, o quadrado) para a aluna com deficiência, que, além de ter conseguido montar a forma [no geoplano], soube dizer também o nome dela (Relatório de Daiana sobre a utilização do livro).

\section{E destacou que:}

A experiência foi ótima e me mostrou que podemos, sim, como educadores, diversificar nossas aulas, sempre pensando na sala na qual estamos inseridos, nos conteúdos e objetivos que queremos alcançar (Relatório de Daiana sobre a utilização do livro).

Diferentemente das participantes já apresentadas, Maria Luzia aplicou o livro em mais de um momento: em atividades realizadas no estágio supervisionado para a docência, em aulas de um projeto de recuperação e em aulas na escola particular na qual atua substituindo professores. Maria Luzia justificou a utilização do livro em razão do:

[...] livro estar vinculado ao dia a dia deles, as crianças não vivem em uma marcenaria, mas todas sentam em uma cadeira! E compreender que em uma história curta e objetiva dá para entender o porquê e o conteúdo é muito atraente. Dar uma aula escrevendo no quadro e repetindo regras é muito fácil para o professor o aluno não entende nada, apenas decora. [...] Os alunos são ótimos, questionaram pontos mais além do livro como retas reversas, entre outros pontos (Questionário de Maria Luzia).

Maria Luzia relatou resumidamente um dos momentos que utilizou o livro. Ela tinha poucos exemplares, por isso realizou a leitura

1042 Educação \& Realidade, Porto Alegre, v. 39, n. 4, p. 1027-1049, out./dez. 2014. Disponível em: <http://www.ufrgs.br/edu_realidade> 
enquanto os alunos, divididos em grupo, acompanhavam e fez questionamentos sobre o enredo e sobre os conteúdos matemáticos.

Uma das dificuldades que ela encontrou foi incentivar os alunos a lerem. Mas, relatou que depois de um tempo decorrido da aula os alunos sentiam vontade de participar. Outra dificuldade referiu-se a falta de conhecimentos prévios dos alunos necessários para compreender o conteúdo, fato que exigiu mais explicações do que as que ela planejou. Também apresentou dificuldades em gerenciar o comportamento dos alunos.

Além disso, Maria Luzia apontou uma dificuldade relacionada à ansiedade de ministrar sua primeira aula:

[...] a primeira aula é inesquecível, você treme inteira e acha que ninguém entendeu nada, que você fracassou, mas quando retorna e os alunos comentam em outra aula, fazem dobraduras e dizem os nomes certinhos do que é plano e o que é dimensional, os ângulos, enfim você descobre o caminho das pedras! Cada aluno tem um conhecimento e soma ao que você está levando, até os que inicialmente resistem e tentam atrapalhar te ensinam (Questionário de Maria Luzia).

Considerando a trajetória, descrita neste artigo, percorrida pelas participantes ao elaborar e implementar os livros e as considerações do estudo de Souza e Oliveira (2013) ${ }^{3}$, este trabalho volta o olhar para a dinâmica da Aciepe analisando a constituição desse espaço formativo e destaca duas propostas importantes nessa dinâmica: a elaboração de um material educativo permeado por momentos de diálogo com o outro, apontamento discutido anteriormente, e o contato com a prática pedagógica propiciado pela implementação desse material.

A seguir tece-se algumas considerações sobre o contato com a prática, na formação inicial, possibilitado pela implementação do livro produzido na Aciepe.

Observa-se que a utilização do livro em sala de aula possibilitou que as participantes voltassem seus pensamentos e ações para o planejamento docente, elas precisaram se organizar, criar imagens de aula, estabelecer objetivos para o ensino e a partir disso selecionar conteúdos e estratégias de ensino eficazes. Essas constatações mostram importantes contribuições da Aciepe, pois, segundo Veenman (1988), a frágil relação entre teoria e prática na formação inicial pode gerar maior choque da realidade.

Assim, fundamental que a formação inicial propicie a aprendizagem de planejar, ou seja, o aprender a definir os objetivos das aulas, o saber quais atividades podem ser realizadas e o quão flexível o docente pode ser. Outros elementos destacados pelo autor que precisam ser enfocados nos cursos de formação inicial objetivando diminuir o choque com a realidade são: a gestão da classe ${ }^{4}$, o saber escutar, o compreender e conhecer as diferentes formas de respostas que os alunos podem dar tendo em vista a abordagem de determinado conteúdo e o saber avaliar.

Educação \& Realidade, Porto Alegre, v. 39, n. 4, p. 1027-1049, out./dez. 2014.1043 Disponível em: <http://www.ufrgs.br/edu_realidade> 
A utilização do livro elaborado possibilitou o almejado contato com a prática, um contato que implica em um pensar sobre, que, segundo Zeichner (1993) não envolve apenas as técnicas e estratégias de ensino e nem ocorre apenas na esfera individual.

Verifica-se que, de certa maneira, esse pensar sobre esteve presente em diferentes momentos da trajetória das participantes na Aciepe. E infere-se que esse movimento pode possibilitar que as participantes não concretizem o ensino de caráter individualista e conservador descrito por Lortie (2002). Individualista no sentido do professor não desejar compartilhar com os pares os dilemas docentes por receio a críticas e o conservadorismo implica em resistir às mudanças profundas e essa resistência também se refere a manter as concepções de ensino, de aprendizagem, sobre as funções do professor e do aluno, sobre as finalidades da educação entre outras que são construídas ao longo da escolarização do docente.

Os dados mostram que as participantes se colocaram em atividade; elas se envolveram em um ambiente no qual puderam questionar e explorar seus saberes e suas práticas, bem como conhecer saberes e práticas de seus colegas e tiveram a possibilidade de fazer esse processo de análise a partir de referenciais teórico-científicos. Conforme destaca Shulman (2004) o colocar-se em atividade é um dos elementos fundamentais para propiciar a aprendizagem docente.

Além disso, constata-se que ao utilizar o livro as participantes, de maneira geral, vivenciaram dificuldades específicas do início da docência (Huberman, 1995), possibilitando o tatear a prática pedagógica. No caso de Ana e Marcela, conforme exposto anteriormente, é possível verificar uma mobilização delas diante das dificuldades. Sendo que para Ana observar a mobilização dos alunos e indícios de suas aprendizagens ao realizarem as atividades por ela propostas lhe propiciou afirmar a certeza de querer ser professora. Em relação às outras participantes aponta-se que, na perspectiva delas, foi importante esse contato mais direto e sistemático com a prática pedagógica.

Esse fato pode ser positivo, pois pode possibilitar que, ao antecipar essas dificuldades, elas iniciem o processo de análise sobre essas situações contribuindo para o enriquecimento de repertório de saberes para a docência.

Isso não significa que as participantes não enfrentarão essas dificuldades nos primeiros anos da docência, mas nesse período possivelmente darão continuidade a esse processo de aprendizagem e baseadas no que aprenderam na formação inicial buscarão novas estratégias, experimentarão, transformarão, ou seja, (re)criarão continuamente sua forma de ensinar. Afinal, a aprendizagem da docência tem continuidade na escola na qual o professor irá atuar, ou seja, a experiência docente trará consistência aos conhecimentos apropriados ao longo da formação inicial.

1044 Educação \& Realidade, Porto Alegre, v. 39, n. 4, p. 1027-1049, out./dez. 2014 Disponível em: <http://www.ufrgs.br/edu_realidade> 
Também é pertinente apontar que apesar de enfrentar dificuldades ao utilizar o livro Ana, Daiana e Maria Luzia relataram que sentiram satisfação ao constatar o engajamento dos alunos nas atividades propostas. Essa satisfação é um elemento positivo, pois de acordo com Lortie (2002), Marcelo García e Vaillant (2009) e outros autores a aprendizagem do aluno é um dos elementos principais que motivam o trabalho docente.

\section{Palavras Finais}

Nessa discussão podemos inferir que a Aciepe investigada constitui-se em uma instância de formação de professores e se configurou como um apoio para o início da docência. Por isso, se faz necessário discutir as iniciativas da Instituição de Ensino Superior (IES) para a concretização desse espaço.

Pode-se estabelecer um paralelo entre esta pesquisa e dois dos princípios apontados por Marcelo García e Vaillant (2009) que devem envolver as instituições formadoras: diversidade e institucionalidade.

A Aciepe se configura como uma modalidade de oferta formativa. Esse aspecto é importante, pois de acordo com Marcelo García e Vaillant (2009) não é viável que exista apenas um ou dois tipos de formação. O professor perpassa por diferentes etapas ao longo de sua carreira possuindo, então, interesses e estilos de aprendizagem diversos, assim como possui múltiplas crenças e ideias. Por isso os autores destacam que não existe uma única modalidade formativa, um único programa de formação que pode ser considerado o mais eficaz, assim é fundamental que haja uma variedade de ofertas formativas.

Além dessas considerações, é importante destacar que o desenvolvimento profissional e a aprendizagem da docência são processos complexos e amplos. A literatura da área de formação docente aponta essa complexidade e os resultados desta pesquisa também validam essa premissa. A elaboração das histórias infantis, por exemplo, expôs as dificuldades que envolvem o saber um conceito e traduzi-lo para apresentá-lo de forma inteligível ao aluno visando sua aprendizagem.

Essa complexidade dos processos formativos exige que as instituições promovam uma diversidade de estratégias formativas, outros momentos, outros espaços, para ampliar as reflexões etc. Este estudo mostrou que a Aciepe configurou-se como uma dessas estratégias sendo bem sucedida.

Isso demanda também um compromisso da IES. O princípio da institucionalidade, apontado por Marcelo García e Vaillant (2009), está presente na Aciepe, uma vez que conta com o compromisso dos membros da instituição objetivando a formação docente de qualidade. Isso é um aspecto importante, pois o desenvolvimento profissional docente está ligado ao desenvolvimento organizativo das instituições formado-

Educação \& Realidade, Porto Alegre, v. 39, n. 4, p. 1027-1049, out./dez. 2014.1045 Disponível em: <http://www.ufrgs.br/edu_realidade> 
ras e precisa ser reconhecido, prestigiado e promovido pelas instituições.

Nesse cenário, é válido destacar que, com a proposta da Aciepe, a IES propõe a articulação entre universidade e escola, entre currículo de formação inicial e da formação contínua, entre professor em exercício e formação inicial. Essa parceira possibilita que a IES não se desconecte do cotidiano escolar, de sua complexidade e de suas demandas. Tal parceria é possível e positiva principalmente quando se considera que uma instituição não tem hegemonia em detrimento da outra. Contudo, isso não ocorre de forma imediata e depende das relações estabelecidas entre os sujeitos envolvidos.

Tecer essas considerações positivas do ponto de vista institucional, não significa ignorar as possíveis tensões que podem ocorrer nessa instância.

Uma tensão pode ser verificada é a quantidade de futuros professores que não concluem a participação na Aciepe. Por ser uma atividade optativa, há graduandos que ao longo do semestre acabam dando prioridade para realizar as atividades obrigatórias do curso.

Outra tensão pode ser constatada quando as formadoras propõe a implementação do livro em sala de aula, após o término da Aciepe, e não é fácil encontrar horários comuns entre os interessados para agendar encontros com o intuito de dialogarem e planejarem a utilização do livro. Considera-se que a interlocução seria mais rica se todos os interessados pudessem participar dos encontros.

Por isso, faz-se necessário buscar, em conjunto com a IES, estratégias para superar essas tensões.

Caminhando para a conclusão deste estudo, pode-se inferir que a Aciepe Histórias Infantis e Matemática nas séries iniciais se configurou como uma instância formativa, que foi planejada e implantada por profissionais da IES, objetivando criar um espaço para impulsionar o desenvolvimento profissional e a aprendizagem da docência dos participantes, tomando como ponto de partida um conteúdo específico (o ensino da matemática) e conectando-o a uma atividade que faz parte do fazer docente, isto é, a implementação e análise de situações de ensino e aprendizagem. Aliada a essas atividades didáticas esteve à produção de material pedagógico, uma ação que, muitas vezes, está distante dos docentes na realidade educacional brasileira.

Isso tudo produziu uma dinâmica formativa que proporcionou: $\mathrm{o}$ diálogo com o outro - com muitos outros, com todos os participantes da Aciepe, com as professoras responsáveis, com o material produzido; o contato do futuro professor com a prática pedagógica; o pensar sobre e aprender elementos específicos da didática; o refletir sobre sua própria prática; o aprender conteúdos específicos; e o se mobilizar para ensinar esses conteúdos.

1046 Educação \& Realidade, Porto Alegre, v. 39, n. 4, p. 1027-1049, out./dez. 2014 Disponível em: <http://www.ufrgs.br/edu_realidade> 
Pensando nas iniciativas da Instituição de Ensino Superior para a concretização da Aciepe, pode-se afirmar que a IES valoriza a formação docente e possui um projeto institucional com recursos humanos, materiais e organizacionais que viabilizem a concretização de práticas formativas. Sendo possível transpor esse espaço formativo para além da abordagem da conexão entre histórias infantis e matemática.

Recebido em 24 de março de 2014 Aprovado em 06 de junho de 2014

\section{Notas}

1 Ficha de catalogação dos livros infantis; diário da elaboração do livro; esboços dos livros; os livros produzidos; plano de ensino para a utilização dos livros em sala de aula; diário reflexivo e relatório das aulas entre outros registros que foram produzidos pelos participantes; diário de campo e relatório de monitoria.

2 Cada participante respondeu de três a quatro questionários que forneceram dados para compreender as aprendizagens, os saberes, as perspectivas, atitudes, valores e motivações das participantes considerando um contexto específico.

3 O estudo de Souza e Oliveira (2013) analisou de forma aprofundada o processo de aprendizagem da docência das participantes e descreveu as dificuldades que as participantes vivenciaram ao cursar a Aciepe. A partir disso indicou que essa atividade curricular contribuiu para o desenvolvimento das dimensões pessoal e profissional das participantes desta pesquisa. As discussões realizadas mostram o “[...] colocar-se em atividade dessas participantes nos momentos de estudos, discussões, elaboração e utilização dos livros. Percebe-se essa mobilização das participantes e o protagonismo delas ao experimentarem, questionarem, dialogarem e estudarem" (Souza; Oliveira 2013, p. 13).

4 A gestão da classe é caracterizada pela direção do processo de instrução, na utilização do tempo, do espaço, dos recursos materiais e dos contatos com os alunos.

\section{Referências}

ANDRÉ, Marli. Estudo de caso: seu potencial na educação. Caderno de Pesquisa, São Paulo, 49, p. 51-54, maio 1984.

ANDRÉ, Marli. Estudo de Caso em Pesquisa e Avaliação Educacional. Brasília: Líber Livro Editora, 2005.

DAVIS, Elizabeth; KRAJCIK, Joseph. Designing Educative Curriculum Materials to Promote Teacher Learning. Educational Researcher, v. 34, n. 3, p. 3-14, 2005.

FERREIRA, Ana Cristina. O Trabalho Colaborativo como Ferramenta e Contexto para o Desenvolvimento Profissional: compartilhando experiências. In: NACARATO, Adair Mendes; PAIVA, Maria Auxiliadora Vilela (Org.). A Formação do Professor que Ensina Matemática: perspectivas e pesquisas. Belo Horizonte: Autêntica, 2006. P. 149-166.

FIORENTINI, Dario. Uma História de Reflexão e Escrita sobre a Prática Escolar em Matemática. In: FIORENTINI, Dario; CRISTOVÃO, Eliane Masteco (Org.). Histórias e Investigações de/em Aulas de Matemática. Campinas: Alínea Editora. 2006. P. 13-36.

Educação \& Realidade, Porto Alegre, v. 39, n. 4, p. 1027-1049, out./dez. 2014.1047 Disponível em: <http://www.ufrgs.br/edu_realidade> 
Aciepe Histórias Infantis e Matemática

GAMA, Renata Prenstteter. Desenvolvimento Profissional com Apoio de Grupos Colaborativos: o caso de professores de matemática em início de carreira. 2007. 240 f. Tese (Doutorado em Educação) - Universidade Estadual de Campinas, Campinas, 2007.

GATTI, Bernardete Angelina. Formação de Professores: condições e problemas atuais. Revista Brasileira de Formação de Professores - RBFP, v. 1, n. 1, p. 90-102, 2009.

HARGREAVES, Andy. Os Professores em Tempo de Mudança: o trabalho e a cultura dos professores na idade pós-moderna. Portugal: MacGraw-Hill, 1998.

HUBERMAN, Michel. O Ciclo de Vida dos Professores. In: NÓVOA, António (Org.). Vidas de Professores. Porto: Porto Editora, 1995.

IMBERNÓN, Francisco. Formação Docente Profissional: formar-se para a mudança e a incerteza. São Paulo: Cortez, 2004.

LORTIE, Dan Clement. Schoolteacher: a sociological study. 2. ed. Chicago: The University of Chicago Press, 2002.

MARCELO GARCÍA, Carlos. Estudio sobre Estrategias de Inserción Profesional en Europa. Revista Iberoamericana de Educación, n. 19, p. 101-143, 1999. Disponível em: <http://www.rieoei.org/oeivirt/rie19a03.htm>. Acesso em: 15 abr. 2009.

MARCELO GARCÍA, Carlos; VAILLANT, Denise. Desarrollo Profesional Docente: ¿Cómo se aprende a enseñar? Narcea, S.A. de Ediciones, 2009.

MIZUKAMI, Maria da Graça Nicoletti et al. Escola e Aprendizagem da Docência: processos de investigação e formação. São Carlos: EduFSCar, 2002.

NACARATO, Adair Mendes et al. Professores e Futuros Professores Compartilhando Aprendizagens: dimensões colaborativas em processo de formação. In: NACARATO, Adair Mendes; PAIVA, Maria Auxiliadora Vilela (Org.). A Formação do Professor que Ensina Matemática: perspectivas e pesquisas. Belo Horizonte: Autêntica, 2006. P. 197-212.

NACARATO, Adair Mendes; MENGALI, Brenda Leme da Silva; PASSOS, Cármen Lúcia Brancaglion. A Matemática nos anos Iniciais do Ensino Fundamental tecendo fios do ensinar e do aprender. Belo Horizonte: Autêntica Ed., 2009.

PASSOS, Cármen Lúcia Brancaglion; OLIVEIRA, Rosa Maria Moraes Anunciato de; GAMA, Renata P. Prenstteter. Grupo de Estudo Colaborativo: matemática conectada com histórias infantis promovendo desenvolvimento profissional. In: IX ENCONTRO NACIONAL DE EDUCAÇÃO MATEMÁTICA: DIÁLOGOS ENTRE A PESQUISA E A PRÁTICA EDUCATIVA, 2007, Belo Horizonte. Anais... Belo Horizonte: SBEM, 2007. P. 1-17.

SHULMAN, Lee S. Those who Understand: knowledge growth in teaching. In: SHULMAN, Lee S. The Wisdom of Pratice: essays on teaching, learning and learning to teach. 1. Ed. United States of America: Jossey-Bass, 2004. P. 189-215.

SOUZA, Ana Paula Gestoso de; OLIVEIRA, Rosa M. M. Anunciato, de. Aprendizagem da docência em grupo colaborativo: histórias infantis e matemática. Educação e Pesquisa, São Paulo, v. 39, n. 4, p. 858-874, out./dez. 2013. Disponível em: <http://www.scielo.br/scielo.php?script=sci_arttext\&pid=S1517$-97022013005000020 \& \operatorname{lng}=\mathrm{en} \& n r m=$ iso $>$. Acesso em: 23 out. 2013.

VEENMAN, Simon. Em Processo de Llegar a ser Profesor: un análisis de la formación inicial. In: VILLA, Alberto (Org.). Perpectivas y Problemas de la Función Docente. Madrid: Narcea, 1988. P. 39-68.

ZEICHNER, Kenneth. A Formação Reflexiva de Professores: ideias e práticas. Lisboa: EDUCA, 1993.

1048 Educação \& Realidade, Porto Alegre, v. 39, n. 4, p. 1027-1049, out./dez. 2014. Disponível em: <http://www.ufrgs.br/edu_realidade> 
Ana Paula Gestoso de Souza é pedagoga, mestre e doutora em Educação pela Universidade Federal de São Carlos. Tem experiência docente nos anos iniciais do Ensino Fundamental e no Ensino Superior. Atua principalmente nos seguintes temas: literatura infantojuvenil, ensino e aprendizagem de matemática, tecnologia informática e formação de professores.

E-mail: ana.gestoso@gmail.com

Rosa Maria Moraes Anunciato de Oliveira é licenciada em Letras e em Pedagogia pela Faculdade de Filosofia Ciências e Letras de Sorocaba, possui mestrado e doutorado em Educação pela Universidade Federal de São Carlos. É professora associada, nível 02 da Universidade Federal de São Carlos. Atua nos seguintes temas: formação de professores, concepções sobre a docência e aprendizagem profissional.

E-mail: rosa@ufscar.br

Educação \& Realidade, Porto Alegre, v. 39, n. 4, p. 1027-1049, out./dez. 2014.1049 Disponível em: <http://www.ufrgs.br/edu_realidade> 